
H. TAKEDA
C. FUJIOKA
R. AOYAGI
S. OKAMURA
T. SHIOSAKI

\section{Enhanced piezoelectric properties of off-stoichiometric strontium bismuth tantalate $\mathrm{Sr}_{0.8} \mathrm{Bi}_{2.2} \mathrm{Ta}_{2} \mathrm{O}_{9}$ ceramics}

Graduate School of Materials Science, Nara Institute of Science and Technology (NAIST), 8916-5 Takayama-cho, Ikoma City, Nara 630-0192, Japan

\section{(C) Springer-Verlag 2005}

The above article was published with the errors in the piezoelectric constants $\left(d_{33}, d_{31}, d_{15}\right)$ of $\mathrm{S}_{0.8} \mathrm{~B}_{2.2} \mathrm{~T}$ ceramics in main text of p. 133 and Table 3 of p. 134. The article showed that the $d_{33}, d_{31}$, and $d_{15}$ values are $10.8,5.2$, and $6.0 \mathrm{pC} / \mathrm{N}$ in the main text and 6.0, 13.0, 10.2 pC/N in Table 3, respectively. The correct piezoelectric constants are $d_{33}=13.0, d_{31}=6.0$, and $d_{15}=10.2 \mathrm{pC} / \mathrm{N}$, respectively. The readers can obtain these values by the relevant equations [1] using the electromechanical coupling factors in Table 2 and dielectric, elastic constants in Table 3. The authors regret this oversight.

\section{REFERENCES}

1 B. Jaffe, W. R. Cook, H. Jaffe, Piezoelectric Ceramics (Academic Press Inc., New York, USA 1971) p. 289
Appl. Phys. A 81, 131 (2005)

DOI 10.1007/s00339-004-3073-x

Published online: 18 November 2004 